\title{
An Analysis of Errors in Online English Writing made by Thai EFL Authors
}

\author{
Sukanda Kongkaew*, Payung Cedar \\ Faculty of Humanities, Naresuan University, Mueang Phitsanulok District, Phitsanulok, Thailand \\ Corresponding Author: Sukanda Kongkaew, E-mail: sukanda_c@hotmail.com
}

\section{ARTICLE INFO}

\section{Article history}

Received: April 19, 2018

Accepted: July 19, 2018

Published: November 01, 2018

Volume: 7 Issue: 6

Advance access: September 2018

\section{Conflicts of interest: None}

Funding: This research is financially supported by the TRF Master Research Grants: TRF-MAG under the support of Thailand Research Fund, and in collaboration with Naresuan University

\begin{abstract}
English writing produced by Thai EFL authors inevitably contains errors of various types. Errors can lead to not only wrong interpretations but also unfavorable criticism. This study is an endeavor to examine errors of English writing made by Thai EFL authors on the Tourism Authority of Thailand Website and to suggest revisions to each error found. To do this, the information on tourist destinations in five provinces in the lower north of Thailand, namely, Phitsanulok, Sukhothai, Phetchabun, Uttaradit, and Tak, was collected. The gathered data consisted of 230 pieces of the information which contained 2,559 sentences. The data were analyzed by applying the framework of Dulay, Burt, \& Krashen's surface structure taxonomy (1982). The results revealed that almost half of all the considered sentences $(44.78 \%)$ contained errors. Based on the framework, errors of omission were found to be the most frequent, followed by those of misformation, addition, and misordering, respectively. Interestingly, the results also showed that the mechanical errors, not in the list of the framework, occurred with the highest frequency. Based upon research findings, online English writing made by Thai EFL authors need more proofreading, especially on the types of errors committed at the highest frequency according to or beyond the framework. However, in focusing on high frequency errors, it is to be noted that miscellaneous occurred the least yet should not be ignored in the correcting process.
\end{abstract}

Key words: English Writing, Error, Error Analysis, Online English Writing

\section{INTRODUCTION}

\section{EFL Writing}

English writing is playing an increasingly important role in international workplaces (Yanalek, 2009). The role of English writing has been substantially evolving in learners, instructors, and various professionals throughout the world (Leki, 2001). However, writing well is not easy. It has been said that writing in English is the most difficult task when compared to listening, speaking, and reading (Rattanadilok Na Phuket \& Othman, 2015). Kukurs (2012) says that even a native speaker can fail to produce a good piece of writing (as cited in Sermsook, Liamnimitr, \& Pochakorn, 2017, p.101). Writing is transforming thought into language and this transformation needs several components like grammar, vocabulary, mechanics, and rhetoric (Byrne, 1984). Apart from differences in grammar and vocabulary, there are issues of letter, word, and text formation, manifested by handwriting, spelling, layout, and punctuation (Oshima \& Hogne, 1991). Iamsui (2014) says it is essential to apply appropriate grammar to express ideas in English writing. Therefore, English writing made by Thai EFL authors cannot avoid committing errors. Praking (2014) says that Thai writing skills are faulty in grammar and Thai officers working for private sectors still need improvement in their English writing skills to be more efficiently.

\section{Statement of the Problem}

Corder (1967) and Richards (1974) remark that as errors are significant, an analysis of errors and error classification is also vital. So far, there have been a number of studies on written text analysis investigating students' writing problems and exploring teachers' practices in the teaching of writing in Thailand. However, there are few studies conducted on written text analysis in the workplace or at an organizational level. In addition, there have been no previous studies on the analysis of written errors on Thailand tourism websites from which tourist destination information in Thailand can be accessed. Even though there was a study on error analysis of documents on Thai culture by Sakha (1999), the number of documents analyzed was only three and all of the three documents were hardcopy brochures which are not as easily accessible as the tourism websites.

Therefore, this current study was an attempt to analyze English writing produced by Thai EFL authors in a new area, that of Internet websites, which have become a great way to communicate in recent decades. The Tourism Authority of Thailand (TAT) website provides a great deal of tourist destination information on Thailand, so it is interesting to analyze its online information which is written in English and produced by Thai authors who use English as a Foreign 
Language (EFL). It, therefore, almost inevitably contains various types of grammatical errors. For example, the following statements have been extracted from the TAT website. This piece of written information about Chan Palace, one of the attractions in Phitsanulok province, contains some errors, which are underlined below:

"...According to the history, it was the birthplace and residence of King Naresuan the Great, one of Thailand's greatest kings. After his reign, the palace was neglected and ruined so that no one knew its existence. The compound later become the site of the premise of the province's premier school, which accidentally discovered the remaining structures during the construction of its new building..."

("Tourism Authority of Thailand", n.d.)

From the above excerpt, the readers might not feel comfortable while they are reading "After his reign, the palace was neglected and ruined so that no one knew its existence." They are likely to be stumped and think that the palace was neglected and ruined for the purpose of not letting other people know its existence. It is fitting and proper to explain what might cause the readers' confusion. Azar (2002) stated that "so that" is used to express a purpose, while "so" is used to express a result. Therefore, grammatically, a subordinating conjunction phrase "so that" should be replaced by a single conjunction "so" in order to express a result of being neglected and ruined; the revised statement can be "After his reign, the palace was neglected and ruined, so no one knew its existence." The other error found in the above excerpt is "become." The word "become" is written in the present form of a verb. A grammatical morpheme of the irregular past tense is omitted. It should be revised and replaced with the irregular past tense form of this verb, "became," in order to be in accordance with its point of view in the past. As a result, corrections of errors found from TAT website should help the readers not to be confused on meaning (Beason, 2001).

In this paper, Error Analysis (EA) was adopted to study the errors that Thai EFL writers have committed in their written information on the TAT website. This study can be directly beneficial to the Tourism Authority of Thailand as well as Thai EFL writers or proofreaders. First, it can be used as a model to raise awareness among Thai writers; they can use this research as a reference to avoid making English writing errors and to recognize a necessary role of future proofreaders in written English information. According to Sakha (1999), when writers recognized the common errors and reminded themselves to check their work, their written texts could be closer to the target language. Second, the suggested revisions for the errors found in the information on the TAT website are properly provided by the first researcher and two other assessors; the TAT website can use them for better quality of tourism information dissemination. Third, this study can potentially contribute to Thailand's tourism, product industry and service sectors in relation to their use of English language that meets the most favorable global standards. When tourists spend their time surfing the Internet and reading the tourist attraction information on the TAT website, they will be satisfied with the way the information is written in English. Prospective visitors can realize how Thai people take the tourism industry seriously by giving importance to thorough preparation and provision of quality written English work.

\section{Purpose of the Study}

The authors were motivated to conduct this research to:

1. examine errors of English writing made by Thai EFL authors on the Tourism Authority of Thailand website about tourist attraction information in the lower northern provincial cluster one,

2. suggest revisions to the errors in written English on the TAT website in the specified five provinces.

\section{Research Questions}

Specifically, this study attempts to answer the following questions:

1. What proportion of error sentences is found in English information produced by Thai EFL authors on the TAT website about tourist attractions in the lower northern provincial cluster one?

2. What are the categories of errors made by Thai EFL authors that are frequently found on the TAT website concerning tourist attractions in the selected five provinces?

3. What revisions can be suggested to the written errors found on the TAT website on tourist attractions in the selected five provinces?

\section{LITERATURE REVIEW}

\section{Theoretical Framework}

In communication, errors occur when language learners speak or write the target language as parts of conversation or composition incorrectly. Dulay et al. (1982) said errors are the flawed part of learners' speech or writing, and they are those parts of conversation or composition that are different from some selected norm of mature language performance. Error Analysis (EA) has been used by applied linguists to examine mistakes that writers make. Brown (1980) defined EA as the process to observe, analyze, and classify the deviations of the rules of the second language and then to reveal the systems operated by learners. Corder (1981) said that Error Analysis is a part of the applied linguistics which focuses on learning process of learners.

Types of errors found in EA can be classified in various ways. In this study, the theory of Dulay et al. (1982) was applied and so were some recent studies; for example, Permadi (2012), Yudharaharja (2013), and Praking (2014). As errors are the flawed side of learners' speech or writing (Dulay et al., 1982), people cannot learn a language without first systematically committing errors. Dulay et al., mentioned four descriptive taxonomies to analyze errors, namely linguistic category taxonomy, surface strategy taxonomy, comparative taxonomy, and communicative effect taxonomy. First, linguistic category taxonomy classifies errors according to ei- 
ther or both the language components and the particular linguistic constituent the error affects. Second, surface strategy taxonomy highlights the way surface structures are altered (omission, addition, misformation, and misordering). Third, comparative taxonomy classifies errors based on comparison between the structure of language learner errors and certain other types of construction. Finally, communicative effect taxonomy deals with errors from the perspective of their effect on the listener or reader.

The second among the four types of descriptive taxonomies, surface strategy taxonomy, which Dulay et al. (1982) proposed, was applied in this study. Surface strategy taxonomy emphasizes the ways surface structures are altered. The authors said learners might omit necessary items or add unnecessary ones; they may give inaccurate items or disorder them. The four classifications of surface strategy taxonomy are enumerated and explained below, to wit:

\section{Omission}

Omission errors are ungrammatical; that is, they are characterized by the missing of an item that must be present in a well-formed sentence. Usually omitted items are some types of morphemes whose absence can affect the over-all understanding of the sentence's idea. Dulay et al. (1982) mentioned two types of morphemes: content morphemes and grammatical morphemes. Content morphemes carry the burden of meaning of a sentence: nouns, verbs, adjectives, adverbs. Grammatical morphemes are little words which play a minor role in conveying the meaning of a sentence.

\section{Addition}

Addition errors are completely different from omission errors. Addition errors mean that there is the appearance of an item which must not be present in a well-formed sentence. They take place in more advanced learners who have already acquired some target language rules. Addition errors are divided into three types: double markings, regularization, and simple additions. Double markings happen when two or more items are marked when only one item is required. Regularization errors in the addition category are those in which a marker that is generally added to a linguistic item is added to exceptional items of the given class that do not take a marker. Simple addition errors occur when there is a use of an item which should not occur in a wellformed sentence and when the error is not a double marking or regularization.

\section{Misformation}

Misformation errors are defined as the use of the wrong form of the structure or morpheme. This type of error is produced when the learner supplies something that is incorrect. Misinformation errors have been divided into three types: regularization, archi-forms, and alternating forms. Regularization errors occur when learners apply the rules used to produce the regular ones to those that are irregular. Archi-forms occur when one member of a class of forms is selected to represent other members in the class. Alternating forms appear when various members of a class are altered with each other.

\section{Misordering}

Misordering errors are the incorrect placement of word order. They happen when learners can select the right forms to use in the right context; however, they still arrange the words incorrectly such as adverbials, interrogatives and adjectives.

\section{Review of Previous Studies}

Previous studies on EA have been conducted in Thailand and many other countries. Most of them were to study students' writing. In this article, only studies on EA in English writing at an organization were reviewed. Their aims shared some of these purposes, namely to find out categories of errors, causes of error occurrences, frequencies of errors, and level of accuracy.

Sakha (1999) studied the errors in the three documents on Thai culture translated into English by the External Cultural Relations Division of the National Culture Commission. She found that the categories of errors consisted of nouns, verbs, articles, prepositions, and punctuation marks. Yanalek (2009), examining the work procedure documents of Nippon Oil Seal Kougyou Precision Components (Thailand) Limited, and Sari (2014), investigating the grammatical errors occurring on Indonesia's official tourism website managed by the Tourism and Creative Economy Ministry of the Republic of Indonesia, also found that articles were the most frequent errors. Permadi (2012), exploring the level of accuracy and the classification of grammatical inaccuracy in the Promotion Media of Tourism in Batu-East Java, and Yudharaharja (2013), studying grammatical error analysis in tourism and object information of Malang City Tour Website, found that omission of plural identification (-s, -es) occurred with the highest frequency. This finding was similar to that of Praking (2014) who examined the grammatical errors found in online announcements in English of the online system of Celestica (Thailand) Limited.

On the aspect of reasons for error occurrences, Sakha (1999) said they were caused by the interlingual errors, while Yudharaharja (2013) revealed that the sources of errors were intralingual errors. Sakha (1999) viewed that the errors appeared due to translators' frequent confusion with the rules concerning the use of the first language and the second language.

In addition, Sakha (1999), Permadi (2012), Praking (2014), and Sari (2014) also found mechanical errors and miscellaneous errors. Sakha (1999) recommended studying other prevalent errors, focusing on spelling mistakes, and calculating error frequencies. Praking (2014) also found errors of comma splices, capitalizations and spellings. Moreover, in the previous studies, the number of the samples was few. Therefore, in this study, a higher number of the samples from the website was analyzed in order to see the clearer picture of English writing made by Thai EFL authors. 


\section{RESEARCH METHOD}

This study consisted of research design, samples, research instrument, data collection, and data analysis; each is explained as follows:

\section{Research Design}

Focusing on analyzing the errors found in online written information on the TAT website, the researchers applied quantitative approach to examine each error. However, error corrections were also qualitatively suggested.

\section{Samples}

For the fulfillment of this research work, the researchers gathered data consisting of 230 pieces of written information of tourist attractions in the lower northern provincial cluster one, publicized on the TAT website from February to March 2017. The five provinces grouped in the lower northern provincial cluster one include Phitsanulok, Sukhothai, Phetchabun, Uttaradit, and Tak (The Office of Strategy Management at Lower Northern Provincial Cluster one, 2015). The data consisted of 230 pieces of attraction information containing 2,559 sentences.

\section{Research Instrument}

The framework of error analysis used in this research was based on Dulay et al.'s surface strategy taxonomy concept (1982). The errors found were classified into four, namely omission, addition, misformation, and misordering; each was explained in the review of literature part of this study. The two types of morphemes in omission error aspect were classified; that is, content morphemes and grammatical morphemes. On one hand, content morphemes included four sub-categories: head noun, subject, main verb, and direct object. On the other hand, the grammatical morphemes were classified into 12 sub-categories: preposition, article, short plural, long plural, auxiliary (do), auxiliary (is, am), copula (is, am), progressive, regular past tense, irregular past tense, third person singular, infinitive marker. Addition error aspect is the opposite of omission; in this aspect, the three types of errors observed were: double markings, regularization, and simple additions. Double marking included six sub-categories: past tense, present tense, negation, equational predicate, object, and twice auxiliary. Regularization was divided into two sub-categories: the regular plural markers "-s", and the past tense markers, "-ed". Simple addition included four sub-categories: the $3^{\text {rd }}$ person singular -s, past tense (irregular), article "a", and preposition. For the misinformation aspect, three types of errors were reported: (1) regularizations; (2) archi-forms, and (3) alternating forms. Like Dulay et al.'s examples of misformation errors, the researchers included nine sub-categories, to wit: reflexive pronoun, regular past, third person singular, auxiliary (does/is), prepositions (at/to), subject pronoun (he/she), possessive pronoun (she's/her), negative (no/not), and quantifiers. Falling under the misordering classification, three types of errors were found: auxil- iary in simple question, auxiliary in embedded question, and adverb. Additional types and sub-types found apart from the framework of this study were also added, and they were verified and agreed upon by the three coders: the first researcher and the other two native speakers. Furthermore, the errors were counted, tabulated, and illustrated to show the overall data, and the collection in numerical data was also described.

\section{Data Collection}

All of the 230 pieces of written information of tourist attractions in the lower northern provincial cluster one on the TAT website (February - March 2017) were copied and pasted on an excel document format and then saved as a softcopy file by the first researcher. The file was given to two coders other than the researchers. Then, the researchers and the other two coders looked for errors, which were then classified according to the framework of Dulay et al. (1982); also properly identified new types of errors were found under each category. The corrections for each error sentence by each coder were also collected.

\section{Data Analysis}

The data of errors found by the three coders were analyzed, classified and counted according to the error analysis model, surface structure taxonomy, presented by Dulay et al. (1982). When there were some different error findings among the coders, the errors that were found were compared and discussed to verify error classification. In case there was more than one coder applying the same measure to the errors, then the errors were counted under their error categories. The average frequency of error types was calculated into percentages according to descriptive statistics. In addition, the revised sentences suggested by the researchers and the coders were further checked and verified by the two coders; after the correct items were verified and finalized, they are going to be given to the office of Tourism Authority of Thailand.

\section{RESULTS AND DISCUSSION}

The results and discussion of this study have been presented in accordance with the three research questions.

\section{The Proportion of Error Sentences Found in English Information Produced by Thai EFL Authors on the TAT Website about Tourist Attractions in the Lower Northern Provincial Cluster One}

After analyzing the data, the number of the analyzed sentences from each province was counted, as was the number of the error sentences. Table 1 below shows the details of these data.

As shown it Table 1, the number of error sentences was 1,146 out of a total of 2,559 sentences that contained in the 230 pieces of tourist attraction information. This means that the proportion of error sentences to the total analyzed sentences was almost one to two, or it can be said that $44.78 \%$ of the total number of sentences contained errors. 
The Categories of Errors Frequently Found in the TAT Website on Tourist Attractions in the Lower Northern Provincial Cluster One

After the data were analyzed, the errors were categorized and counted according to the error analysis model of Dulay et al.'s surface strategy taxonomy (1982). In addition, errors were also categorized into mechanical errors and miscellaneous errors which were not in the lists of the aforementioned taxonomy concept, but emerged from the data analysis; for example, improper spacing, spelling/typo, hyphen and capitalization. Table 2 provides the data about main categories, frequency, percentage, and rank of errors found in the TAT website on tourist attractions in the lower northern provincial cluster one.

Table 2 illustrates the results of analyzing the 1,146 error sentences. It was found that there were 2,225 written errors which were categorized into six main categories. The mechanical error category was found to be the most frequently committed error with 812 errors, or $36.49 \%$ of the total occurrences. This included omission (781 errors, or $35.10 \%$ ), misformation (362 errors, or $16.27 \%$ ), addition (222 errors, or $9.98 \%$ ), misordering (33 errors, or $1.48 \%$, and miscellaneous errors (15 errors, or $0.67 \%$ ). The findings of each main categories are described as follows.

\section{The distribution of omission errors}

After analyzing the data, the omission errors were classified into three types; content morphemes, grammatical mor- phemes, and punctuation omission. The first two types were classified according to Dulay et al.'s surface strategy taxonomy (1982), but the last group emerged from the data analysis. Table 3 provides data about the distribution, frequency, and percentage of the omission error sub-categories found in the data analysis.

Table 3 illustrates that the omission error sub-category which occurred the most was the omission of short plural, '-s', (18.18\%), followed by the omission of articles, 'the' $(17.54 \%)$, the omission of articles, 'a' or 'an' $(9.86 \%)$, and the omission of prepositions, $(8.45 \%)$.

\section{The distribution of misformation errors}

The misinformation errors found in this data analysis were divided into two types: regularization, and archi-forms and alternating forms. Table 4 provides the data about the distribution, frequency, and percentage of misformation error sub-categories found in the data analysis.

Table 4 shows that the misformation error sub-category occurring the most was the misformation of preposition $(22.65 \%)$. This was followed by the misformation $(18.51 \%)$ and the misformation of punctuation $(16.85 \%)$.

\section{The distribution of addition errors}

The addition errors found in this data analysis were divided into three types: double markings, regularization, and simple additions. Table 5 shows the distribution, frequency, and percentage of the addition sub-categories found in the data analysis.

Table 1. Number of written errors found on the TAT website on tourist attractions in the lower northern provincial cluster one

\begin{tabular}{lccc}
\hline Province & No. of pieces of the analyzed information & No. of the analyzed sentences & No. of the error sentences \\
\hline Phitsanulok & 41 & 426 & 207 \\
Sukhothai & 31 & 238 & 130 \\
Phetchabun & 58 & 708 & 298 \\
Uttaradit & 31 & 346 & 174 \\
Tak & 69 & 841 & 337 \\
Total & 230 & 2,559 & 1,146 \\
\hline
\end{tabular}

Table 2. Main categories, frequency, percentage, and rank of the errors found in the TAT website on tourist attractions in the lower northern provincial cluster one

\begin{tabular}{lccc}
\hline Error Category & Frequency of errors & Percentage of errors found (\%) & Rank \\
\hline Categories according to Dulay et al.'s surface strategy taxonomy (1982) & & 35.10 & 2 \\
1. Omission & 781 & 16.27 & 3 \\
2. Misformation & 362 & 9.98 & 4 \\
3. Addition & 222 & 1.48 & 5 \\
4. Misordering & 33 & & 1 \\
Other categories that emerged from the data analysis & 812 & 36.49 & 6.67 \\
1. Mechanical errors & 15 & 100 \\
6. Miscellaneous errors & 2,225 & \\
Total
\end{tabular}


Table 3. Distribution of the sub-categories of omission errors

\begin{tabular}{|c|c|c|}
\hline Type of errors & Frequency & Percentage $(\%)$ \\
\hline Content morphemes & 112 & 14.36 \\
\hline Conjunction & 39 & 5.00 \\
\hline Main verb & 32 & 4.10 \\
\hline Subject & 14 & 1.79 \\
\hline Head noun & 13 & 1.67 \\
\hline Direct object & 7 & 0.90 \\
\hline Modifier & 7 & 0.90 \\
\hline Grammatical morphemes & 552 & 70.68 \\
\hline Short plural: -s & 142 & 18.18 \\
\hline Article: the & 137 & 17.54 \\
\hline Article: a, an & 77 & 9.86 \\
\hline Preposition: to, on, in, for, etc. & 66 & 8.45 \\
\hline Relative pronoun/pronoun & 22 & 2.82 \\
\hline Present/past participle & 20 & 2.56 \\
\hline Auxiliary: is, am, are & 20 & 2.56 \\
\hline Long plural: -es & 18 & 2.30 \\
\hline Irregular past tense & 13 & 1.66 \\
\hline Copula: is, am & 10 & 1.28 \\
\hline Regular past tense: -ed & 9 & 1.15 \\
\hline Third person singular & 8 & 1.02 \\
\hline Infinitive marker: to & 5 & 0.64 \\
\hline Auxiliary: do & 2 & 0.26 \\
\hline Irregular count noun & 2 & 0.26 \\
\hline Progressive & 1 & 0.13 \\
\hline Punctuation: comma, period, etc. & 117 & 14.98 \\
\hline Total & 781 & 100.00 \\
\hline
\end{tabular}

Table 5 shows that the addition error sub-category that occurred the most is addition articles $(27.93 \%)$. This is followed by addition plural forms (15.32\%) and addition preposition (13.06\%).

\section{The distribution of misordering errors}

The misordering errors found in this data analysis contained six sub-categories, namely, auxiliary in embedded question, adverb, auxiliary in inversion, negative complement, adjective position, and punctuation. Table 6 illustrates the distribution, frequency, and percentage of misodering sub-categories found in the data analysis.

Table 6 shows that the misordering error sub-category that occurred the most is adjective position, in which adjectives were put in the wrong order. The misordering of adjectives $(39.39 \%)$, which is followed by misordering of punctuations (24.24\%) and misordering of adverbs (21.21\%).
Table 4. Distribution of misformation errors

\begin{tabular}{lcc}
\hline Types of errors & Frequency & Percentage (\%) \\
\hline Regularization errors & 2 & 0.55 \\
Regular past & 2 & 0.55 \\
Archi/Alternating forms & 360 & 99.45 \\
Preposition: at/to, etc. & 82 & 22.65 \\
Determiner: a, an, the, etc. & 67 & 18.51 \\
Punctuation & 61 & 16.85 \\
Verb tense/voice & 56 & 15.47 \\
Subject-verb agreement & 29 & 8.01 \\
Suffix & 25 & 6.91 \\
Present/past participle & 17 & 4.70 \\
Infinitive/gerund & 5 & 1.38 \\
Passive form in intransitive & 4 & 1.10 \\
verb & & \\
Pronoun & 4 & 1.10 \\
Quantifiers & 3 & 0.83 \\
Subject pronoun: he/she & 2 & 0.55 \\
Possessive pronoun & 2 & 0.55 \\
Predicate: verb-copula & 2 & 0.55 \\
Prefix: un-, im-, etc. & 1 & 0.28 \\
Total & 362 & 100 \\
\hline
\end{tabular}

Table 5. Distribution of addition errors

\begin{tabular}{lcc}
\hline Types of errors & Frequency & Percentage (\%) \\
\hline Double markings & 4 & 1.80 \\
Past tense & 2 & 0.90 \\
Object & 1 & 0.45 \\
Twice auxiliary & 1 & 0.45 \\
Regularization & & \\
Regular plural markers: -s & 13 & 5.86 \\
Past tense marker: -ed & 4 & 1.80 \\
Simple addition & 201 & 90.54 \\
Article: a, an, the & 62 & 27.93 \\
Plural form & 34 & 15.32 \\
Preposition & 29 & 13.06 \\
Redundancy & 24 & 10.81 \\
Punctuation: comma, & 23 & 10.36 \\
apostrophe & & \\
Third person singular & 17 & 8.11 \\
Past tense & 7 & 3.15 \\
Two main verbs & 4 & 1.80 \\
Total & 222 & 100 \\
\hline
\end{tabular}

\section{The distribution of mechanical errors}

The mechanical errors found in this data analysis consisted of four sub-categories: spacing errors, spelling errors, hyphen errors and capitalization errors. Table 7 shows the distribution, frequency, and percentage of mechanical sub-categories found in the data analysis. 
Table 7 shows that the mechanical error sub-category that occurred most often is space error $(60.22 \%)$. This is followed by capitalization or no capitalization (20.94\%), spelling or typos (16.38\%), and hyphen $(2.46 \%)$.

\section{The miscellaneous errors}

The miscellaneous errors are the ones which cannot be classified into any of the classifications above. After analyzing the data from the TAT website, it was found that there were 15 written errors, $0.68 \%$ of the total error occurrences, which were categorized as miscellaneous errors. Some of these errors are shown in Table 8.

\section{Suggested Revisions to the Written Errors Found on the TAT Website on Tourist Attractions in the Lower Northern Provincial Cluster One}

As mentioned earlier, the researchers suggest corrections to the errors found on the TAT tourism website with the intention to make information dissemination on the website clearer for the prospective travelers. The revised sentences have been verified, finalized, and shown in Table 8 . The examples of the six error categories have been drawn and presented in Table 8 .

Table 8 shows samples of sentences containing errors and their revisions. These samples were drawn from the 1,146 error sentences out of 2,559 sentences in the 230 pieces of written information of tourist attractions on the TAT website covering the period from February to March 2017.

\section{DISCUSSION}

According to the findings, it was discovered that the mechanical errors that were not a part of the study's framework

Table 6. Distribution of misordering errors found on the TAT website

\begin{tabular}{lcc}
\hline Types of errors & Frequency & Percentage (\%) \\
\hline Adjective position & 13 & 39.39 \\
Punctuation & 8 & 24.24 \\
Adverb & 7 & 21.21 \\
Auxiliary in inversion & 2 & 6.06 \\
Negative complement & 2 & 6.06 \\
Auxiliary in & 1 & 3.03 \\
embedded question & & \\
Total & 33 & 100 \\
\hline
\end{tabular}

Table 7. Distribution of mechanical errors

\begin{tabular}{lcc}
\hline Type of errors & Frequency & Percentage (\%) \\
\hline Space & 489 & 60.22 \\
Capitalization/no & 170 & 20.94 \\
capitalization & & \\
Spelling/typo & 133 & 16.38 \\
Hyphen & 20 & 2.46 \\
Total & 812 & 100.00 \\
\hline
\end{tabular}

were the most frequent. The proportion of mechanical error occurrences was more than one-third of the total errors found. This is different from previous studies mentioned in the literature review (Praking, 2014; Permadi, 2012; Sari, 2014) which found omission errors to have the highest frequency of occurrence. The reasons for this can be the type and amount of information used. This current study offered some insights for online English writing made by Thai EFL authors.

\section{Mechanical and Miscellaneous Errors}

Mechanical errors were found to be the most frequently committed errors in the online write-ups in the said website. Out of the total mechanical error occurrences, the space errors occurred with the greatest frequency. This is followed by capitalization errors, spelling or typo errors, and hyphen errors. For the reason that mechanical errors occurred with the highest frequency, it is recommended that any written information to be posted on the TAT website be checked carefully before and after posting, with the mentioned categories to being the focus of corrective attention. Certainly, even though these categories of mechanical errors might not affect the idea of attraction information, revisions of errors can make the information easily readable and understandable. The following excerpt which was extracted from the information in Phitsanulok on Kaeng Chet Khwae National Park is an example.

Excerpt: The Royal Forest Departmentwas reported from Phitsanulok's Royal Forest Departmentthat the area of Kaeng Chet Khwae National Park and PhuDaeng Ron National Park are beautiful sightseeing area and the surrounding forests are still keeping its fertility and are appropriate to be counted as National Parks.

Revision: The Royal Forest Department was reported from Phitsanulok's Royal Forest Department that the area of Kaeng Chet Khwae National Park and Phu Daeng Ron National Park are beautiful sightseeing area and the surrounding forests are still keeping its fertility and are appropriate to be counted as National Parks.

For all practical purposes, it is suggested that having proofreaders, translators, website supervisors, or students trained in finding these categories of errors can help improve electronic writing or posting.

The other aspect of errors emerged in written English on the website and included in the data analysis is miscellaneous errors. The miscellaneous errors that the researchers noticed from the website included informal contractions, an incorrectly reduced adverbial phrase, incorrect periods, unrelated information, an improper subject, duplication, use of unnecessary words, and applying similar words. Although the miscellaneous errors were the least error category found, their occurrences can possibly make website viewers who might be prospective visitors, evaluate the information negatively. For example, in the $7^{\text {th }}-9^{\text {th }}$ sentences of the destination information in Uttaradit province, as shown in Table 8, there were three sentences found that they were not related to the tourist attraction information. The tourist attraction information is about Baan Ta Rue, 
Table 8. Some examples of the suggested revisions to error sentences found on the TAT website

\begin{tabular}{lll}
\hline Item & Error sentences and suggested revisions & Error type \\
\hline Phitsanulok: & The art gallery displays over a hundred masterpieces of renowned Thai & Omission: Short plural:-s \\
$3^{\text {rd }}$ sentence & artists such as Thailand's former Prime Minister Chuan Leakpai, national & \\
& artist in visual arts such as Sawasdi Tantisuk, Phun Ketchamrat, Priyuan & \\
& Aruchata, other celebrated artists such as Pratuang Emjaroen, Chavalit & \\
& Saemprungsuk, Chung Moonphinit and Chalermchai Khosipipat. \\
& Revision: The art gallery displays over a hundred masterpieces of \\
& renowned Thai artists such as Thailand's former Prime Minister Chuan & \\
& Leakpai, national artists in visual arts such as Sawasdi Tantisuk, Phun \\
& Ketchamrat, Priyuan Aruchata, and other celebrated artists such as & \\
& Prating Emjaroen, Chavalit Saemprungsuk, Chung Moonphinit, and & \\
& Chalermchai Khosipipat.
\end{tabular}

Sukhothai: $\quad$ Located on the north of Mahathat Temple, make sure you visit the unique $157^{\text {th }}$ sentence chedi near CharotWithithong Road and the small twelve chedis. Revision: It's located on the north of Mahathat Temple. Make sure you visit the unique chedi near Charot Withithong Road and the twelve small chedis.

Sukhothai: $230^{\text {th }}$ sentence

Phetchabun: $132^{\text {nd }}$ sentence

Phetchabun: $355^{\text {th }}$ sentence

Uttaradit: $4^{\text {th }}$ sentence

Uttaradit: $7^{\text {th }}-9^{\text {th }}$ sentence

Tak: $198^{\text {th }}$ sentence

Tak: $252^{\text {nd }}$ sentence

Historians had founded numerous archaeological evidences in the area, such as Chinese porcelains and Hinduism statues of gods, they later summarized it was first build as a Hindu religious structure and was later turned into a Buddhism temple.

Revision: Historians had found numerous pieces of archaeological evidence in the area, such as Chinese porcelains and Hinduism statues of gods, they later summarized it was first built as a Hindu religious structure and was later turned into a Buddhism temple.

The pagoda is the architecture in Sukhothai style and the applied Rattanakosin style.

Revision: The pagoda is built in the architecture in Sukhothai style and the applied Rattanakosin style.

It is in in the in Nam Nao National Park which covers 4 districts of Petchabun namely Lom Kao, Lom Sak and Nam Nao as well as Kon Sarn in Chaiyaphum.

Revision: It is in Nam Nao National Park which covers 4 districts of Petchabun namely Lom Kao, Lom Sak and Nam Nao as well as Kon Sarn in Chaiyaphum.

The rafts for the tourists consist of temporary and overnight.

Revision: The rafts for the tourists consist of temporary and overnight service.

mple was located at the junction in the heart of the city.

It is always full of Buddhist.

Therefore, the villagers changed the name of the temple from Wat Ton Makam to WatTummatippatai.

It is a shopping paradise for gemstones lovers as it is has now become a major trading spot for jade and gems and for general shopaholics who can shop at the municipal market (behind Siam Hotel) for cheap Burmese clothing, cigarettes, decorative items, original Burmese blankets and slippers, etc.

Revision: It is a shopping paradise for gemstone lovers as it has now become a major trading spot for jade and gems and for general shopaholics who can shop at the municipal market (behind Siam Hotel) for cheap Burmese clothing, cigarettes, decorative items, original Burmese blankets and slippers, etc.

It's the waterfall where water flowing on the levels of limestone where each level features scenic view which worth to take small trek. Revision: It's the waterfall where water flows on levels of limestone where each level features scenic view which is worth taking a small trek.
Omission: Subject and copula

Misordering: Adjective

Mechanical: Space and

Capitalizing

Omission:

Irregular past tense

Addition:

Regular plural marker:-s and

Regularization:

Past tense marker: -ed

Omission: Main verb and preposition

Mechanical: Typo

Omission: Direct object

Miscellaneous: These sentences were not related to this attraction information.

Addition: Double marking on twice auxiliary

Simple addition on plural form at noun as adjective

Misformation: Present participle Addition: article "the" Omission: copula "ist" Misformation: Infinitive/gerund 
which is a village on the lake shore, but the three misplaced sentences went on to describe a temple occurring at the bottom of it.

\section{Omission, Addition, Misinformation and Misordering Errors}

When the four aspects of errors categorized based on the framework of Dulay et al.'s surface structure taxonomy concept (1982); omission, addition, misformation, and misordering, were compared, omission errors were found with the highest frequency. This was followed by misformation errors, addition errors, and misordering errors. Among the sub-categories in the omission error aspect, omitting short plural "-s", similar to the previous studies (Praking, 2014; Yudharaharja, 2013), was found with the highest frequency of occurrence of the total error occurrences. Some other obvious omission errors found were omitting article "the", omitting commas or periods, omitting article "a/an", omitting preposition, omitting conjunctions, and omitting main verbs. In terms of content morphemes and grammatical morphemes, the percentage of error occurrences of content morphemes, was as almost one-fifth of that of grammatical morphemes, $24.81 \%$. Despite its lower percentage of error occurrences, it appeared that the content morpheme omission resulted in conveying the message. For example, the following extract was drawn from the attraction information on Baan Ta Rue, one of the 31 tourist attraction data in Uttaradit Province: "The rafts for the tourists consist of temporary and overnight." What was omitted is a direct object, "service", at the end of the sentence: "The rafts for the tourists consist of temporary and overnight service." Therefore, analyzing content morpheme omission based on the framework of Dulay et al.'s surface structure taxonomy concept (1982) can be a helpful instrument to find errors and improve written works of translators, proofreaders, or students because it will result in successful conveying of sentence meaning. This will not cause website viewers to be disoriented especially those readers who might not be able to easily predict or think of a word that is omitted.

Although misformation errors ranked $3^{\text {rd }}$ in terms of error frequency, there are some interesting findings with regard to how this error type appeared in the collected data. After finding and categorizing the errors, on archi/ alternating forms, the three coders agreed to create additional sub-categories: subject-verb agreement, present/past participle, verb tense/voice, determiner, prefix, suffix, infinitive/gerund, passive form in intransitive verb, pronoun, predicate replacing verb-copula, and punctuation. Interesting findings under this category were found in the area of overregularization. There were only two error occurrences of regular past overregularization; one was found in the information about the tourist attraction in Uttaradit Province named "Luang Phor Phet"; "This Buddha image in the attitude of subduing Mara, sitting in diamond posture with short outer robe, is casted in bronze with spectacular characteristics." The regular marker, "-ed", was used in place of an irregular one as in casted for cast. This error sentence might not be serious since the intended meaning is still there; however, another overregularized error found seemed to convey a meaning different from the intended one. This extract was drawn from the written information about Wat Si Sawai, one of the 31 tourist attraction data in Sukhothai on the TAT website: "Historians had founded numerous archaeological evidences in the area, such as Chinese porcelains and Hinduism statues of gods, they later summarized it was first build as a Hindu religious structure and was later turned into a Buddhism temple." The regular marker, "-ed", was used in place of irregular one as in founded for found. This misformation error can be an example of the less frequent error occurrence, but it highly affects the intended meaning. Therefore, this category of error occurrences found based on the framework of Dulay et al. (1982) can be a good option to consider for translators, proofreaders, or students, as they will be more cautious when producing written English works. Moreover, other sub-category errors were found which fell under the misinformation category. The findings revealed that prepositions were misformed at the highest frequency of the total error occurrences. This was followed by misformed determiners, misformed punctuation, misformed verb tense and voices, misformed subject-verb agreements, and misformed suffixes.

Addition errors ranked fourth among the categories of frequently committed errors. Three types of addition errors were classified: double marking, regularization, and simple additions. In the double marking aspect, there were only four occurring errors. Two of these were past tense double marking, one was object double marking, and the other was twice auxiliary double marking. The percentage of this error occurrence was only $0.18 \%$ of the total error occurrences. In the regularization aspect, the percentage of occurrence was $0.76 \%$. After finding and classifying the errors on simple additions, the three coders agreed to create more additional sub-categories: plural form, two main verbs, redundancy, and punctuation. Among the three sub-categories under addition errors, it was found that simple addition errors occurred with the highest frequency of occurrence. Simple addition of article errors was the most frequently committed error in this category of the total error occurrences. It was followed by simple plural form addition error, prepositions, redundancy, and punctuation. Since addition errors are concerned with the presence of items which must not appear in well-formed sentences, analyzing these errors thoroughly based on the framework of Dulay et al.'s surface structure taxonomy concept (1982) can be helpful to improve the works of those whose work nature of work requires posting English information online.

In relation to misordering errors, it was found that this error type ranked fifth among the total recorded errors. Two types of misordering errors were found: auxiliary in embedded question and adverb. Additional sub-types emerged and were then added into this category: adjective order, punctuation, auxiliary in inversion, and negative complement. Analyzing these incorrect placements of morphemes or groups 
of morphemes in written online information can favor translators, proofreaders, or students to produce or deal with well-formed or well-arranged sentences in English which necessitate proper placement of a morpheme or groups of morphemes.

\section{CONCLUSION}

The purposes of this study were to examine errors of English writing made by Thai EFL authors on the TAT website and to suggest revisions of errors found to the Office of Tourism Authority of Thailand based on the framework of Dulay et al.'s surface structure taxonomy (1982). The results showed that among the categories suggested by Dulay et al. (1982), omission had the highest frequency of occurrence, followed by misformation, addition, misordering, and miscellaneous errors. However, it was also found that mechanical errors, which were outside the study's framework, were the most frequent errors. This was different from the studies reviewed previously in the literature review, so it has been recommended that any future study applying this framework include mechanical errors into its EA.

Among all of the sub-category errors, space errors in the mechanical error type occurred with the highest frequency. Interestingly, the findings revealed that although mechanical errors were found to be the most frequently occurring, they do not have much effect on conveying the meaning of content. Conversely, the other error categories were found with the fewest frequencies of error occurrences, but having a much greater influence on conveying meaning. The results indicated that to produce a good piece of online English writing, Thai EFL authors should work on applying appropriate grammar as well as mastering mechanics.

Consequently, this study suggests some implications of its findings as follows. Firstly, the suggested revisions to all of the error sentences found in the pieces of the tourist attraction information in the Lower Northern Provincial Cluster One publicized on the TAT website are to be given to the Office of Tourism Authority of Thailand in Phitsanulok. Secondly, the findings obtained from this study could be used as a guideline for creating English training courses in order to develop writing skills for Thai officers who are responsible for translating online information, for the proofreaders to proofread information on websites, for IT officers in charge of organization website supervision, or for students whose interest is on improving their writing skills in English for their future careers. Thirdly, being a major source of tourist information for the country, the TAT has a great opportunity to promote the beauty and culture of Thailand. This is one reason additional training for Thai EFL writers of English is important. Using this research as a model of specific aspects to work on, training modules can be developed to enhance Thai authors' English writing skills. This also has potential to lead to future research for the TAT in areas such as, creating surveys for tourists on TAT website readability, and reader satisfaction with information on the website. Finally, on pedagogic implications, it is recommended that a lesson concerning online English writing be included in an English writing course so that students can produce a piece of well-written English work.

\section{ACKNOWLEDGEMENTS}

The researchers would like to express their appreciation to the TRF Master Research Grants: TRF-MAG under the support of Thailand Research Fund, and to Naresuan University which provide financial support for this research study. Also, this study cannot be completed without the help of Thomas Locke and James A. Riggins in relation to error analysis aspect.

\section{REFERENCES}

Azar, B.S. (2002). Understanding and using English grammar. White Plains, NY. Pearson Education.

Byrne, D. (1984). Teaching writing skill. London: Longman Group.

Beason, L. (2001). Ethos and Error: How Business People React to Errors. College Composition and Communication, 53, 33-64. Retrieved May 25, 2016, from http:// www.personal.psu.edu/mjw321/teaching/courselinks/ beason.pdf

Corder, S. P. (1967). The significance of learners' errors. International Review of Applied Linguistics, International Review of Applied Linguistics in Language Teaching, 5(4), 161-170. Retrieved May 25, 2016, from http:// files.eric.ed.gov/fulltext/ED019903.pdf

Corder, S. P. (1981). Error analysis and interlanguage. Oxford: Oxford University Press.

Dulay, H., Burt, M., \& Krashen, S. (1982). Language two. Oxford: Oxford University Press.

Iamsui, C., (2014). An Analysis of Grammatical Errors in Srinakharinwirot University Students' Writing (Master's thesis). Retrieved May 25, 2016, from http://ir.swu. ac.th/xmlui/handle/123456789/3671

Leki, L. (2001). Material, educational, an ideological challenges of teaching EFL writing at the turn of the century. International Journal of English Studies, 1, 197-209.

Oshima, A., Hogne A., (1991). Writing Academic English, ( $3^{\text {rd }}$ ed.), New York: Addison Wesley Longman.

Permadi, M. B. (2012). Grammatical Accuracy in the Promotion Media of Tourism in Batu-East Java (Bachelor's thesis). Retrieved May 25, 2016, from http://jurnal-online.um.ac.id/article/do/detail-article/1/7/84

Praking, N. (2014). An Analysis of Grammatical Errors in On-line English Announcement: A Case Study of Celestica (Thailand) Limited (Master's thesis). Retrieved May 25, 2016, from http://opac.lib.buu.ac.th/index.html

Rattanadilok Na Phuket, P., \& Othman, N. B. (2015). Understanding EFL Students' Errors in Writing. Journal of Education and Practice, 6(32), 99-106.

Richards, J.C., (1974). Error analysis: Perspectives on second language acquisition. London: Longman.

Sakha, S. (1999). An Error Analysis of Documents on Thai Culture Translated by the External Cultural Relations Division of the National Culture Commission (Master's thesis). Phitsanulok, Thailand: Naresuan University. 
Sari M. E. C., (2014). Grammar Errors in the English Version of Indonesia's Official Tourism Website. Yogyakarta, Indonesia: Gadjah Mada University. Retrieved May 20, 2016, from http://etd.repository.ugm.acid

Sermsook, K., Liamnimitr, J., \& Pochakorn, R. (2017). An Analysis of Errors in Written English sentences: A Case Study of Thai EFL Students. English Language Teaching, 10(3), 101-110. http://dx.doi.org/10.5539/elt. v10n3p101

The Office of Strategy Management at Lower Northern Provincial Cluster One. (2015). Retrieved May 25, 2016, from http://www.osmnorth-s1.moi.go.th/Documentdownload/data.pdf
Tourism Authority of Thailand. (n.d.). Chan Palace. Retrieved May 25, 2016, from http://www.tourismthailand. org/Attraction/Chan-Palance-4736

Yanalek, J. (2009). An Error Analysis of English in Work Procedure Document: A Case Study of Nippon Oil Seal Kougyou Precision Component (Thailand) Limited (Master's thesis). Retrieved May 25, 2016 from http:// www.thailis.or.th/tdc

Yudharaharja, A. P. (2013). Grammatical Error Analysis in Tourism Objects Information of Website of Malang City Tour (Master's thesis). Retrieved May 15, 2016, from http://jimbastrafib.studentjournal.ub.ac.id/index.php/ jimbastrafib/article/view/187/163 